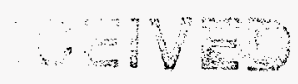

Juस 17997

251
June, 1996

\title{
Wire ageing with the TEA photocathode.
}

\author{
J. Va'vra \\ Stanford Linear Accelerator Center, Stanford University, \\ Stanford, CA 94309, U.S.A.
}

\begin{abstract}
Recently several RICH prototypes successfully tested a gaseous TEA photocathode. However, its wire ageing behavior is unknown. In principle, TEA is a more strongly bonded molecule than TMAE, and, as a result, one would expect better wire ageing behavior. This paper explores this question.
\end{abstract}

DISTRIBUTION OF THIS DOCUMENT IS UNLIMITED

Presented at the Conference on Photon Detectors : Beaune, France, June 24-28, 1996.

This work was supported by Department of Energy contract DE-AC03-76SF00515. 


\section{DISCLAIMER}

This report was prepared as an account of work sponsored by an agency of the United States Government. Neither the United States Government nor any agency thereof, nor any of their employees, make any warranty, express or implied, or assumes any legal liability or responsibility for the accuracy, completeness, or usefulness of any information, apparatus, product, or process disclosed, or represents that its use would not infringe privately owned rights. Reference herein to any specific commercial product, process, or service by trade name, trademark, manufacturer, or otherwise does not necessarily constitute or imply its endorsement, recommendation, or favoring by the United States Government or any agency thereof. The views and opinions of authors expressed herein do not necessarily state or reflect those of the United States Government or any agency thereof. 


\section{DISCLAIMER}

Portions of this document may be illegible in electronic image products. Images are produced from the best available original document. 


\section{INTRODUCTION}

This paper contributes to the basic understanding of how photocathode materials behave at high rates in typical applications of photon detectors based on a gas amplification method. Tests with TMAE (Tetrakis-dimethylamino-ethylene; $\left.\left[\left(\mathrm{CH}_{3}\right)_{2} \mathrm{~N}\right]_{2} \mathrm{C}=\mathrm{C}\left[\mathrm{N}\left(\mathrm{CH}_{3}\right)_{2}\right]_{2}\right)$ and $\mathrm{CsI}$ photosensitive materials were described previously [1,2]. Tests with the TEA molecule (Tri-ethyl-amine; $\left.\left(\mathrm{C}_{2} \mathrm{H}_{5}\right)_{3} \mathrm{~N}\right)$ are presented now.

The present measurement was motivated by the very good results obtained from the TEAbased prototypes of the College de France [3] and Cornell [4] groups. We were was also encouraged by the Cornell group to compare TEA and TMAE in the same apparatus, since this yields similar systematic errors.

One may expect that TMAE wire ageing is faster because the TMAE molecule is more fragile than the TEA molecule. The TMAE molecule has an ionization potential of only $\sim 5.4 \mathrm{eV}$, and its lowest dissociation energy may be as low as $2.7 \mathrm{eV}$; TEA's ionization potential is $\sim 7.8 \mathrm{eV}$.

Photosensitive molecules such as TMAE or TEA, or their ageing products, may have a large volume resistivity when deposited on the cathode surfaces. Therefore the possibility exists of exciting self-sustaining cathode currents by a high radiation dose [1].

Finally, TEA has been used successfully to quiet down noisy wire chambers in the past. This is presumably because TEA has a very short absorption length $(\ell \sim 0.6 \mathrm{~mm})$ for hard UV photons originating from atomic excitations in the avalanche. Consequently, it was also interesting to investigate whether TEA might serve as a "magic" additive to normal gases in order to reduce drift chamber ageing rate.

\section{RESULTS}

Following the experience of the Cornell group, we did not clean the TEA in any special way. It was simply transferred from a manufacturer's bottle [5] to a bubbler in an oxygen free glove box filled with $\mathrm{N}_{2}$ gas. Prior to a test, ethane gas was passed through the bubbler for $\sim 24$ hours. This approach is very different from that used in TMAE applications, where the TMAE liquid must first be cleaned by a combination of water washing, filtering and pumping before being used in applications involving long electron drift distances [6].

A carrier gas, $\mathrm{C}_{2} \mathrm{H}_{6}$, at $1 \mathrm{~atm}$ was used in obtaining all results presented in this paper. For the TEA tests, the bubbler was kept at $15^{\circ} \mathrm{C}$ using a thermostatic bath, and the detector vessel and associated plumbing were kept at ambient temperature. For the TMAE tests in this paper, the bubbler was kept at $40^{\circ} \mathrm{C}$, and the detector vessel and associated plumbing were kept at $\sim 50^{\circ} \mathrm{C}$ (in the past, we have not seen any ageing dependence on the TMAE concentration [1]). The ageing tests were performed in the setup used previously [1], and the MWPC was instrumented with 7 , 
20 and $33 \mu \mathrm{m}$ diameter carbon wires [7]. The chamber used a nickel-plated cathode, which was washed in ethanol prior to use. The chamber operated at a total wire gain of about $3-4 \times 10^{5}$, and dark current was kept below $0.5 \mathrm{nA}$, as in all previous TMAE ageing tests. Radiation was provided by a $\sim 5 \mathrm{mC} \mathrm{Fe}{ }^{55}$ source, which simulates well the ageing caused by $X$-ray backgrounds present at colliding beam machines. We did not perform ageing tests with a UV source. A typical starting ageing current density was $\sim 200 \mathrm{nA}$ per $5 \mathrm{~mm}$ of wire length for all measurements mentioned in this paper. The role of the rate at which a TMAE ageing test should be performed was investigated in CRID Note\#36 in ref.1. At that time, we did not see any difference in ageing performance when the starting current density was varied from $\sim 5$ to $\sim 200 \mathrm{nA}$ per $5 \mathrm{~mm}$ of wire length.

The experiment was carried out under the same strict conditions required for TMAE operation, i.e. electropolished stainless steel tubing and VCR fittings were used, the ageing vessel was made of stainless steel, and the oxygen content was maintained at a level of less than one ppm. Other construction materials present in the MWPC were G-10 (unpainted with epoxy), 5 min. epoxy, and conducting epoxy, solder, etc.

Fig. 1 shows the wire ageing results with $\mathrm{C}_{2} \mathrm{H}_{6}+\mathrm{TEA}$ for various anode wire diameters. One can see that the gain change correlates with the anode wire diameter. This is similar to the result obtained during the TMAE tests [1].

Fig. 2 shows a comparison between TMAE and TEA wire ageing for the $33 \mu \mathrm{m}$ diameter wire. A relative gain decrease of $\sim 20 \%$ is observed after $\sim 4 \mathrm{mC} / \mathrm{cm}$. The corresponding result with $\mathrm{C}_{2} \mathrm{H}_{6}+\mathrm{TMAE}$ indicated the same drop after only $\sim 1 \mathrm{mC} / \mathrm{cm}$.

Fig. 3 shows a comparison between TMAE and TEA wire ageing for a wire diameter $20 \mu \mathrm{m}$. One can see that the TMAE ageing rate is considerably faster. A relative gain decrease of $-20 \%$ is observed after $\sim 1.5 \mathrm{mC} / \mathrm{cm}$ with $\mathrm{C}_{2} \mathrm{H}_{6}+\mathrm{TEA}$, and after only $\sim 0.2 \mathrm{mC} / \mathrm{cm}$ with $\mathrm{C}_{2} \mathrm{H}_{6}+\mathrm{TMAE}$. We conclude that the TEA wire ageing rate (20\% gain drop) appears to be slower than that of TMAE by a factor of 4-7.

As in the TMAE case [1], we have also found that the anode wires can be "regenerated" by passing a small current through them. This heats the wire to a high temperature $\left(>300^{\circ} \mathrm{C}\right)$, and causes the deposits to evaporate. We heated the wires for few minutes using a current of $\sim 25 \mathrm{~mA}$. The "regenerated" wires showed ageing behavior similar to that of the "brand new" wires.

Another critical question is whether TEA is less susceptible to self-sustaining cathode currents. Such a problem is recognized by removing the source, and observing whether the cathode current disappears instantly or lingers for a long time (various time constants were observed, ranging from tens of seconds to minutes, including just bursts of charge [1]). An example of the onset of such currents in TMAE-based gas is shown in Fig. 3, where a sudden flattening of the ageing curve can be seen in one test, and the residual current persisted even after the source was removed. TMAE- 
based gases show such a sensitivity quite readily. As was suggested in Ref.1, such sensitivity may be related to high TMAE resistance which results probably from the very rigorous purification procedure adopted (water is removed). TEA, based on the experience of only 12 ageing trials, appears to be less sensitive to self-sustaining cathode currents. In this sample of 12 , we have observed only one case in which a self-sustaining current was triggered. However, care has to be exercised in this regard if one wants to operate a system with a large number of wires. One can attempt to cope with such a problem by running at as low a wire gain as possible, or by including an additive (perhaps a small amount of water), or by having a very clever high voltage system which is capable of recognizing the onset of such currents, and automatically lowering the voltage. Clearly, a low wire gain operation of about $3-4 \times 10^{4}$, as envisaged in the Cornell detector, is a step in the right direction.

\section{CONCLUSIONS}

1. The TEA wire ageing rate (20\% gain drop) appears to be slower than that of TMAE by a factor of 4-7.

2. The TEA wire ageing rate is inversely proportional to the anode wire diameter. This is similar to TMAE.

3. We found that a TEA-aged anode wire surface may be regenerated as a result of the heating which accompanies the passage of a small current through the wire. This is similar to TMAE.

4. We have observed one case in $\sim 12$ tries in which a normal wire ageing process turned into a self-sustaining cathode current condition, i.e. a current persisted even after the source was removed. The best way to protect against this problem in a system consisting of a large number of wires is to try to run at as low a wire gain as possible.

\section{ACKNOWLEDGEMENTS}

I thank M. McCulloch for excellent technical support during this test.

\section{FIGURE CAPTIONS}

1. Wire ageing results with $\mathrm{C}_{2} \mathrm{H}_{6}+\mathrm{TEA}$ for anode wire diameters 7,20 and $33 \mu \mathrm{m}$.

2. Wire ageing results with $\mathrm{C}_{2} \mathrm{H}_{6}+\mathrm{TMAE}$ and $\mathrm{C}_{2} \mathrm{H}_{6}+\mathrm{TEA}$ for wire diameter $33 \mu \mathrm{m}$.

3. Wire ageing results with $\mathrm{C}_{2} \mathrm{H}_{6}+\mathrm{TMAE}$ and $\mathrm{C}_{2} \mathrm{H}_{6}+\mathrm{TEA}$ for wire diameter $20 \mu \mathrm{m}$.

\section{REFERENCES}

[1] J. Va'vra, IEEE Trans. Nucl. Sci., NS 34, No.1, p.486, February 1987; CRID Note \#36, SLAC, 1987; IEEE Trans. Nucl. Sci., NS 35, No.1, p.487, February 1988;

Nucl.Instr.\&Meth. A367 (1995) 353-357. 
[2] J. Va'vra, A. Breskin, A. Buzulutskov, R. Chechik, and E. Shefer, "Study of the CsI photocathodes : volume resistivity and ageing", SLAC-PUB-96-7095, presented at the Conference on Photon Detectors, June 24-28, Beaune, France.

[3] J. Seguinot et.al., Nucl.Instr.\&Meth., A350 (1994) 430; R. Arnold et.al., Nucl.Instr.\&Meth., A314 (1992) 465; M. French et.al., Nucl.Instr.\&Meth., A324 (1993) 511.

[4] S. Playfer, M. Artuso, A. Efimov, M. Gao, S. Kopp, R. Mountain, F. Muheim and S. Stone, "Prototype Studies for the CLEO III RICH", presentation at the RICH Workshop, Uppsala, Sweden, June 11-18, 1995.

[5] TEA was purchased from Fluka Chemika-BioChemica Co., catalog number 90342.

[6] A. Abe et. al., Nucl.Instr.\&Meth., A343 (1994) 74.

[7] The $7 \mu \mathrm{m}$ wire was made by Toho Rayon Co., Japan (it is also used in the SLD CRID detectors); the $20 \mu \mathrm{m}$ wire was made by Energy Science Lab., CA 92121-2232, U.S.A.; the $33 \mu \mathrm{m}$ wire was made by Textron Co., U.S.A. 


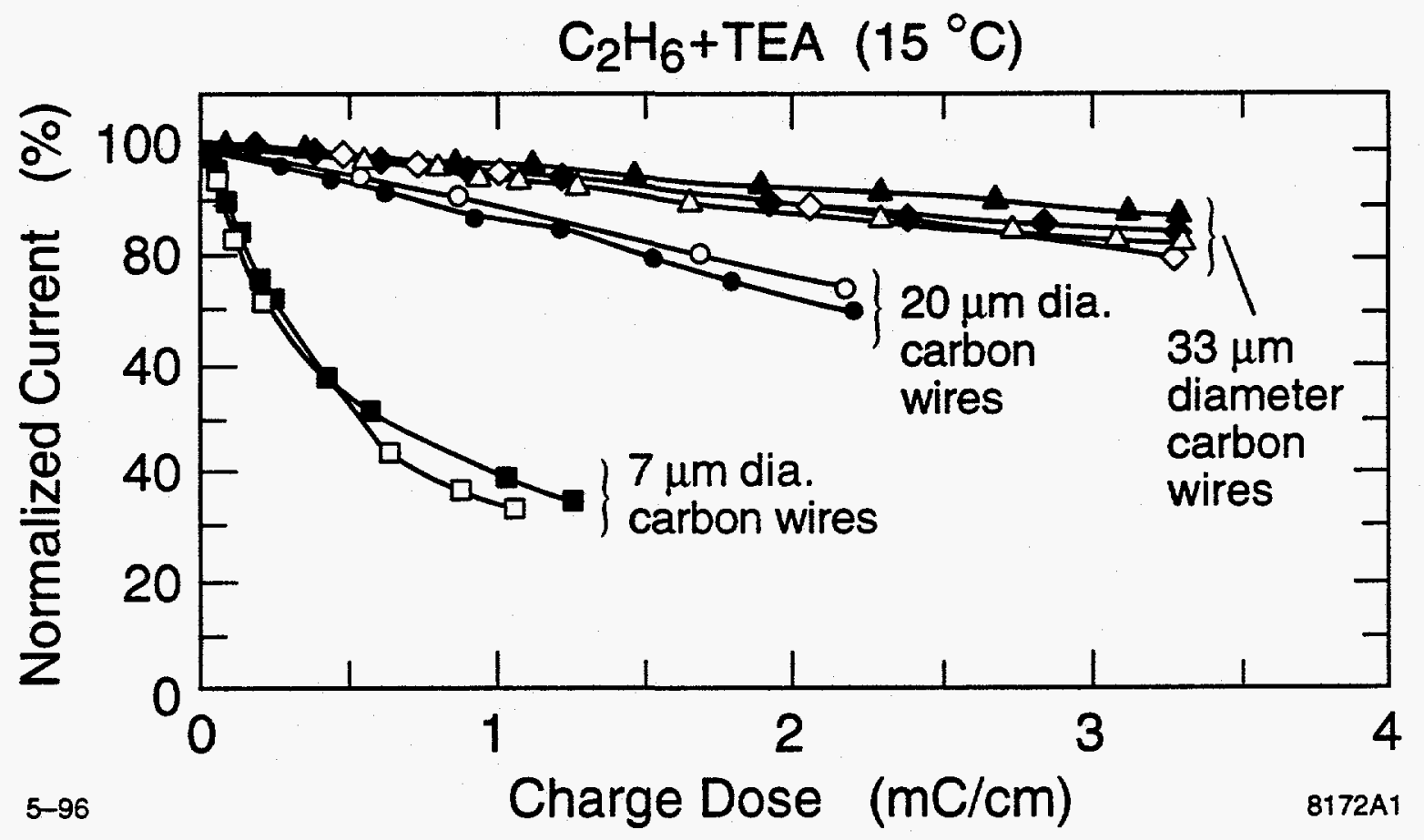

Fig. 1 
TMAE vs TEA

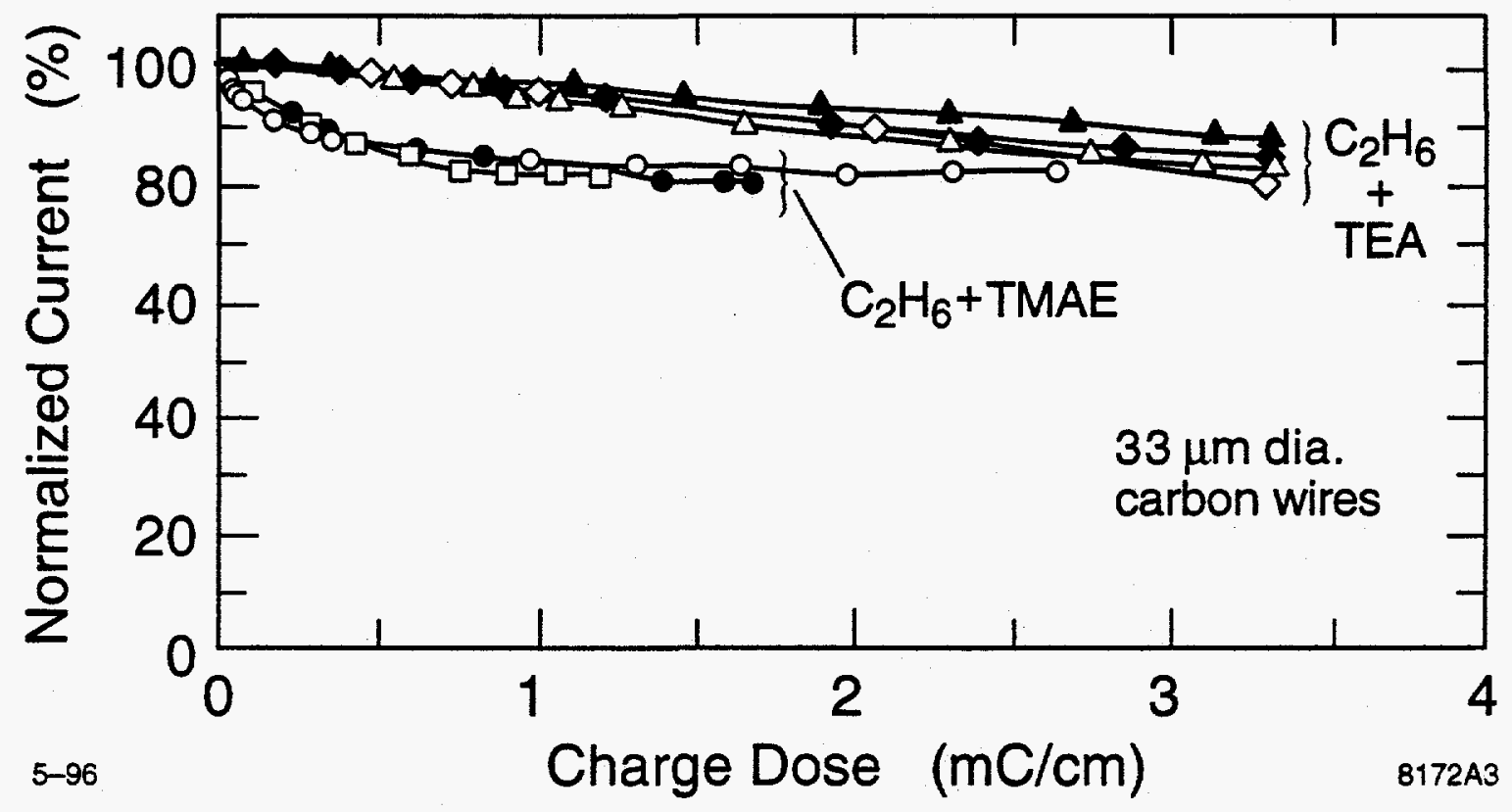

Fig. 2 
TMAE Vs TEA

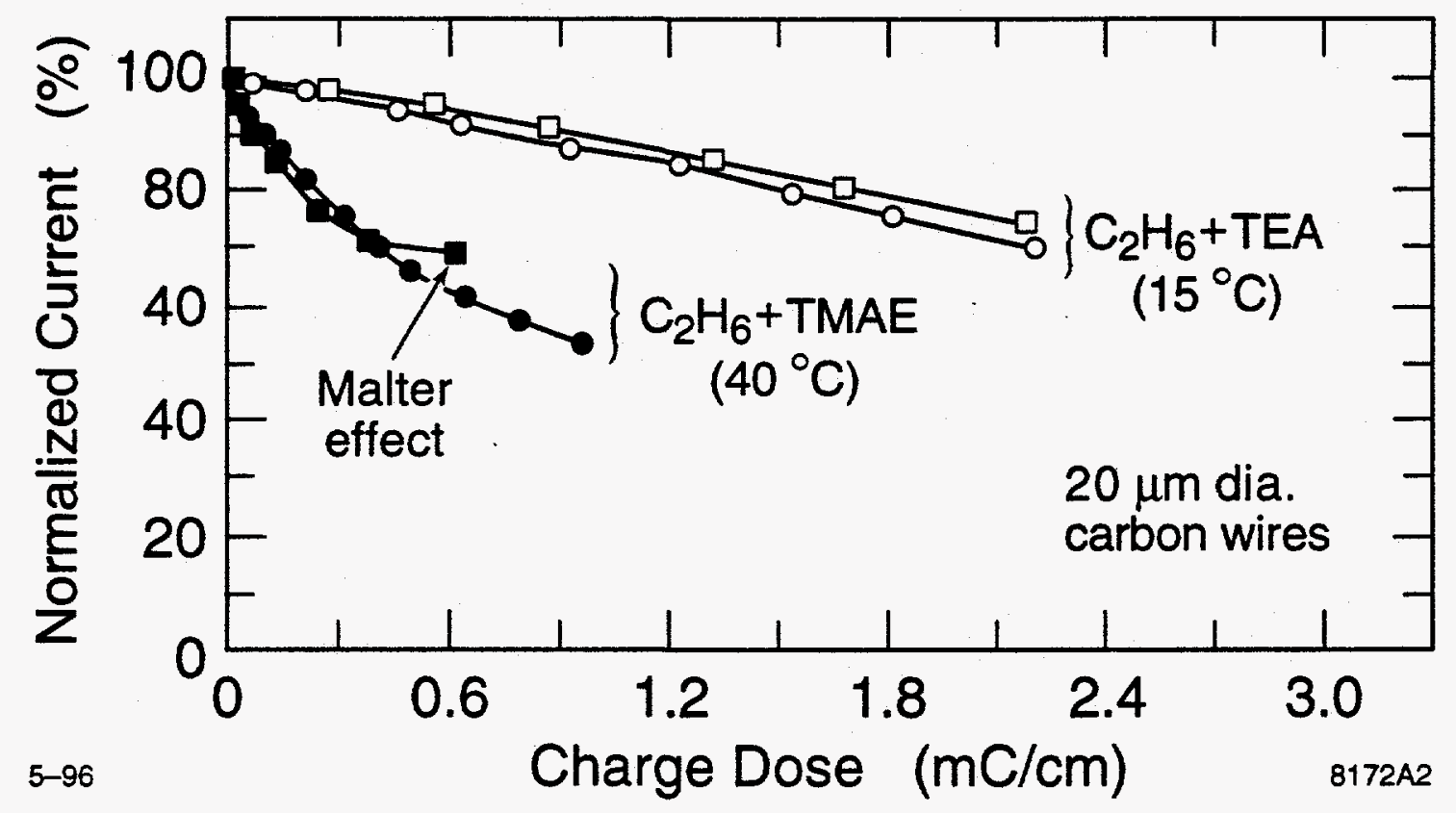

Fig. 3 